\title{
An Analysis of Journal Use by Structural Biologists with Applications for Journal Collection Development Decisions
}

\section{Claudia Lascar and Loren D. Mendelsohn}

\begin{abstract}
This paper defines and examines structural biology as a subdiscipline of molecular biology. Using bibliometric methodologies, it analyzes the publication and citation patterns of a sample group of structural biologists from multiple institutions. The citations analyzed covered a very large subject range, demonstrating the multidisciplinary nature of this subfield. The results were consistent with several models for journal selection. These models were used to compile a short list of specialized titles supporting structural biology. Although the research was performed on a relatively small group of local researchers, it has broader applications for other institutions attempting to develop similar collections.
\end{abstract}

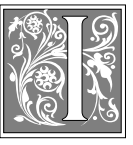

n December 1998, several research institutions in New York State formed a consortium to promote research in protein and nucleic acid structure. ${ }^{1}$ The City College, one of the senior colleges of the CUNY system, was chosen to be the site for the consortium's magnetic resonance research laboratory. This facility was to be designated the Center for Structural Biology (hereinafter referred to as "the Center"). In early 1999, the City College Library was asked to develop a plan for the support of the scientists, drawn from all of the participating institutions, who would be using this new facility. Thus, the authors needed to identify key library resources, both print and online, that had the following characteristics:

- They had to be useful to those who would be using the Center's research facilities.
- They had to be familiar to these same scientists (i.e., at least some of the resources had to be materials that the scientists were already using at their home institutions).

For the purposes of the plan, these resources were limited to two categories: print and online research journals (the focus of this paper), and online indexing and abstracting services. Thus, this research is focused on determining an appropriate model based on bibliometric methodologies for accurately identifying such resources.

\section{What Is Structural Biology?}

The first part of the task was a matter of definition: A working definition of structural biology had to be established. To do this, the authors examined its development as a subdiscipline of molecular biology and the related discipline of biochemistry. 
Molecular biology and biochemistry both attempt to understand the physicochemical basis of life, but from different perspectives. Traditionally, biochemistry has sought to understand the nature of chemical reactions within the cell and is concerned primarily with transformation of small molecules (twenty to thirty atoms) in living systems and the transformation of energy within living systems. Although biochemistry has some concern for large molecules (macromolecules) and

\section{One of the main advantages of NMR methods is that they do not require crystals; they are performed on solutions.}

their structure, such concern is limited to the role they play in the chemistry of the smaller molecules. Biochemists tend to use classical methods of chemistry to carry out their investigations. Molecular biology, on the other hand, is concerned with the interrelationships between the structure and function of the macromolecules in living systems (i.e., proteins, polysaccharides and nucleic acids). Molecular biology was an outgrowth of biochemistry, virology, genetics, and cell biology; in its beginnings, it relied heavily on X-ray crystallography and quantum mechanical studies. John C. Kendrew gave an excellent summary definition of molecular biology and how it differs from biochemistry:

\section{What is characteristic, however, and what may perhaps serve to differ- entiate it from biochemistry, is the emphasis and reliance in molecular biology on concepts derived from, and only derivable from, a knowl- edge of complex three-dimensional structures. ${ }^{2}$}

Kendrew further argued that molecular biology could be broken into two subdisciplines, each of which developed in relative isolation from the other. He called one discipline the informational school, which was concerned with the storage and expression of genetic information in nucleic acids. Key events in the advancement of this school were the breakthrough discovery by James Watson and Francis Crick of the double-stranded helical structure of DNA in 1953 and the determination of the genetic code by Marshall Nirenberg and Severo Ochoa in the early 1960s. The entire field of genetic engineering is based on this school, whose greatest achievement to date has been the mapping of the human genome, which was accomplished in 2000 . Kendrew called the second discipline the conformational school, which was concerned primarily with the relationship between molecular structure and function in the living cell. This discipline became known as structural molecular biology or, simply, structural biology. The ultimate goal of structural biology is to determine how to predict protein structures and functions from the information stored on nucleic acids.

Structural biology pursues this goal by establishing correlations between the levels of structural organization of biological macromolecules (primarily proteins and nucleic acids). Christopher M. Smith wrote a useful discussion of how this procedure has been applied to proteins in recent years. ${ }^{3}$ The first level of organization is the primary structure. Biological macromolecules are polymers: long chains of small molecules (monomers) bonded together. The primary structure is the order in which the monomers are strung together-the amino acid (or peptide) sequence for proteins and the nucleotide sequence for nucleic acids. Secondary structure refers to the folding or coiling of the original polymer chains by the means of hydrogen bonds (the double helix in the case of DNA or the alpha helix and beta sheet in the case of polypeptide chains of proteins). The tertiary structure refers to how these secondary structures fold upon themselves to form larger structural units, such as the supercoiling for DNA or the arrangement of the alpha helix and beta sheet regions for polypeptides. Some proteins have a quaternary 
structure, in which a number of polypeptide chains, each having its own tertiary structure, aggregate to form one large molecule.

The structure of nucleic acids is relatively simple in comparison with the structures of proteins. Nucleic acids are made up of linear sugar-phosphate backbones with regular repeating structures of only four monomers. The variations in sequence can be enormous, but the structures remain relatively similar because the monomers are chemically similar. In the case of DNA, two of these linear molecules are joined together to form the double-helix structure elucidated by Watson and Crick. This simpler structure is in keeping with the more limited function of nucleic acids, which (with a very few exceptions) serve only to store and transfer information. By contrast, proteins have very complicated structures. They are composed of long linear polypeptide chains. The monomers that make up these chains are twenty very diverse amino acids. The chemical diversity of these amino acid monomers results in an enormous diversity of structure and an equally huge diversity of function. This diversity of structure is necessitated by the role that proteins play, catalyzing virtually all of the chemical functions of life and serving many structural and mechanical functions as well.

\section{Beginnings of Structural Biology}

Structural biology emerged in the late 1930s when it became possible to determine the tertiary and quaternary structure of biological macromolecules. Scientists accomplished this through the use of X-ray crystallography, which enabled them to calculate with great accuracy the precise location of groups of atoms within the crystal. Initially, such determinations were a difficult and time-consuming process, simply because of the newness of the technique and the lack of a thorough understanding of the geometry of the chemical bonds that formed the structures. Also, there were difficulties in preparing crystals of macromolecules that were large enough to use with this technique. The work of Linus Pauling on bond angles and atomic distances in the late 1940s considerably simplified the entire process, but the process still remained quite difficult. The first correlation of structure with function was achieved by David C. Phillips in 1965, when he determined the structure of lysozyme (an antibacterial enzyme present in egg white and many human secretions) and proposed a mechanism based on that structure. Philips published a useful summary of his

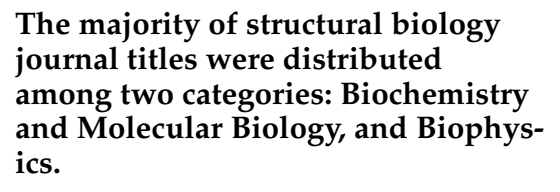

work in $1966 .{ }^{4}$ By 1970 , only eleven structures had been solved. ${ }^{5}$ Over the years, improvements in instrumentation, crystallization techniques, and methods of data processing have considerably expedited the determination of such structures. Instrumentation improved as a result of the development of more intense $\mathrm{X}$-ray sources, such as synchrotron radiation. Crystallization became considerably simpler with the application of recombinant DNA techniques, which greatly simplified the process of obtaining large homogeneous protein samples. With more intense $X$-ray sources and larger crystals, researchers were able to increase the resolution of the technique, enabling them to determine with relative precision the location even of individual atoms. The computerization of data processing, as well as the establishment of increasingly large structure libraries for purposes of comparison, greatly expedited the derivation of structures from the X-ray data. Moreover, as techniques of nuclear magnetic resonance (NMR) spectrometry have been expanded and refined, researchers have been able to apply such methodologies to macromolecular structure determination. One of the main advantages of NMR methods is that they do not require crystals; they are performed on solutions. 
Their disadvantage is that NMR data are most useful only for relatively small proteins. In cases where NMR and crystallographic techniques can be used together, investigators can determine macromolecular structures with great accuracy and high resolution.

\section{Use of Citation Data}

The nature of the authors' user group (composed mostly of researchers from institutions other than City College) was such that journal use data were extremely difficult to obtain. The user group was unresponsive to both telephone and email requests for use data, and the authors did not have access to the interlibrary loan statistics. The best data that could be obtained were anecdotal, based on a few face-to-face discussions with some of the scientists and interviews with the librarians at their home institutions. The interviews gave a sense of what sources the researchers used most frequently but yielded no hard data. The authors also examined their library collections and electronic resources to determine those materials to which the researchers were accustomed to have access. Because of the lack of hard use data, the authors decided to use citation and publication patterns as their primary means of quantifying the importance of structural biology journals. Finally, because of the focus of the planned facility on NMR techniques, the authors determined to give greater weight to journals covering that topic.

Such bibliometric analysis was discussed at length by Howard D. White and Katherine W. McCain and has been used as a tool for evaluating journal collections for more than seventy years. ${ }^{6}$ There have been several applications of this technique to the management of science journal collections in the past few years. ${ }^{7-9}$ One of the more important tools in performing these analyses is Journal Citation Reports (JCR), an annual that has been published since 1976 as an adjunct to the ISI Citation Indexes. JCR ranks each listed journal according to its impact factor, a ratio "calculated by dividing the number of current year citations to the source items published in that journal during the previous two years." ${ }^{10}$ Obviously, some preselection must take place because the cited references are not drawn from all journals, but only from those deemed relevant by ISI. Nevertheless, the JCR impact factor is an excellent indicator of the relative importance of one journal among others in a given year, especially with respect to those in the same or similar fields. Furthermore, M.B.M. Campbell has shown that the percentage of use by a department correlates well with percentage of total citation by a department. ${ }^{11}$ Elizabeth Pan also indicated that there is a statistically significant correlation between the ranking of biomedical journals and use count. ${ }^{12}$ She demonstrated that in most cases, high citation count indicated high use and low citation indicated low use. For these reasons, the authors' initial efforts at identifying important structural biology journals focused on the use of JCR categories. When the authors examined those categories that appeared to be relevant, however, they realized that the information the categories contained was not immediately useful. The majority of structural biology journal titles were distributed among two categories: Biochemistry and Molecular Biology, and Biophysics. Although some of the titles were very highly ranked within these categories, it was impossible to determine their relevance to structural biology without further evaluation. Thus, the authors decided to examine the citation and publication patterns of a specific group of scientists drawn from the researchers who would be members of the Center, thus enabling the authors to calculate more focused and relevant impact factors for the journals under examination.

In taking this approach, the authors followed the pattern of the vast majority of citation studies that have been done in the sciences, nearly all of which have used faculty publications as the source of data. This has been the case regardless of the scientific discipline, whether it fell within the physical sciences (e.g., Amy Dykeman's 1994 study) or the biological sciences (e.g., 
the studies on the literature of molecular biology by Julie M. Hurd, Deborah D. Blecic, and Rama Vishwanatham and by Janet Hughes). ${ }^{13-15}$ This study is the first application of this technique to structural biology. Such a study is needed for the following reasons:

- Structural biology is a distinct subfield of molecular biology that uses specific biophysical techniques such as X-ray crystallography and NMR spectroscopy to determine the three-dimensional structure and function of macromolecules.

- It is a multidisciplinary field.

- It developed independently and had a slower beginning in comparison with the rest of molecular biology.

- Structural biology has experienced tremendous growth and development in the past decade with concomitant growth of its literature, as demonstrated by the emergence of new journal titles dedicated to the field: Nature Structural Biology (in 1994), Structure (in 1993), Folding and Design (in 1996) (the latter two titles merged in 1999 to form Structure with Folding and Design), Journal of Biomolecular Structure (in 1996), Journal of Biomolecular NMR (in 1991), Journal of Biochemistry, Molecular Biology and Biophysics (in 1997), Macromolecular Structures (in 1991), Journal of Molecular Modeling (in 1997), and others. Moreover, the proportion of structural biology articles in the older and more established journal titles has been steadily increasing.

- As a discipline, it has direct applications for the pharmaceutical and biotechnology industries.

- As a discipline, it has direct relevance to the whole of science.

- Research institutions are establishing structural biology departments and programs that require support from their libraries.

\section{Methodology and Data Collection}

The first step was to create a set of source items from which references would be taken. Using information from the Center's promotional brochure, eleven key researchers were identified. To this number, one participating scientist was added from the authors' own institution. A search in Web of Science (ISI's Web-based version of Science Citation Index) was conducted to form a list of these researchers' publications from 1995 to 1999 . The authors used any articles that had references, which included reviews and some letters, but excluded meeting abstracts and editorial materials. In this way, a list of 218 articles was compiled with a median of thirteen articles per author. Two of the authors were disqualified as outliers because one had produced sixty-eight articles and the other only two during the time period examined. The remaining sample contained 146 articles, representing the work of nine researchers (table 1). The journals in which these articles appeared are listed in table 2 by frequency. To ensure equal representation within this group, the authors used a maximum of thirteen articles per author (the median) for the analysis. If a researcher had produced more articles, the authors randomly selected thirteen of them for analysis. This process yielded a total of 106 articles containing 4,283 cited references. Table 3 displays a ranking of these references by type of literature. Finally, when calculating the impact factors, the authors divided the total number of citations by the total number of articles per journal, rather than using Garfield's more rigorous method described above. This was necessary because of the small size of the study sample.

\section{Data Analysis}

Using this data set, it was determined that the average number of cited references per article was 40.45 (table 1). It should be noted that most of the original research articles had a high number of references, which provided a considerable quantity of data, thus partially offsetting the small number of authors in the sample. Of the cited references, 95.1 percent were to journal articles (table 3). This high proportion is consistent with established theory that the majority of scholarly communication in the sci- 


\begin{tabular}{|c|c|c|c|c|c|}
\hline \multicolumn{6}{|c|}{$\begin{array}{c}\text { TABLE } 1 \\
\text { Researchers and Their Publications }\end{array}$} \\
\hline Name & Affiliation & $\begin{array}{l}\text { Articles } \\
\text { Produced }\end{array}$ & $\begin{array}{l}\text { Articles } \\
\text { Used }\end{array}$ & $\begin{array}{l}\text { Total } \\
\text { Cites }\end{array}$ & $\begin{array}{c}\text { Average } \\
\text { Ref. per } \\
\text { Article }\end{array}$ \\
\hline Ann McDermott & Columbia University & 13 & 13 & 505 & 38.85 \\
\hline John Cavanagh & Wadsworth Center & 17 & 13 & 549 & 42.23 \\
\hline Ruth Stark & CUNY & 17 & 13 & 425 & 32.69 \\
\hline Ming-Ming Zhou & $\begin{array}{l}\text { Mount Sinai School } \\
\text { of Medicine }\end{array}$ & 11 & 11 & 382 & 34.73 \\
\hline David Cowburn & Rockefeller University & 29 & 13 & 568 & 43.69 \\
\hline Milton Werner & Rockefeller University & 12 & 12 & 530 & 44.17 \\
\hline Mark Girvin & $\begin{array}{l}\text { Albert Einstein School } \\
\text { of Medicine }\end{array}$ & 12 & 12 & 439 & 36.58 \\
\hline Maria Tasayco & CUNY & 6 & 6 & 244 & 40.67 \\
\hline John Kuriyan & Rockefeller University & 29 & 13 & 641 & 49.31 \\
\hline Total & & 146 & 106 & 4,283 & 40.45 \\
\hline
\end{tabular}

entific community takes place in the journals. It also should be noted that this group of 4,073 cited references represented 386 different journal titles. Table 4 ranks journals according to the frequency with which they were cited in the 106 selected articles within the user group. The authors chose only those titles that were cited more than five times. This was because of fair-use considerations under copyright law and their implications for library collections. Using this standard, a total of fifty-eight journals was selected. Table 4 shows that, as a rule, the authors in the study tended to cite articles appearing in the better-established journals with greater frequency than those appearing in the newer structural biology titles. Nevertheless, some of the newer titles were cited with a surprisingly high frequency, most notably Nature Structural Biology and Journal of Biomolecular NMR, which were among the top ten. Moreover, when the data in tables 2 and 4 are compared, close similarities can be observed between the citation and publication patterns of the user group. Again, articles were published most frequently in the better-established journals, yet the two newer titles of Journal of Biomolecular NMR and Structure with Folding and Design were among the top ten.
These patterns are consistent with S.M. Dhawan's model, proposed twenty years ago and widely accepted today. ${ }^{16}$ This journal selection model proposes a technique based on permutations on whether a journal is cited, abstracted, or used and establishes five categories of journals in decreasing order of usefulness:

1. journals that are cited, abstracted, and used;

2. journals that are abstracted, used, but not cited;

3. journals that are cited, used, but not abstracted;

4. journals that are used, but neither abstracted nor cited;

5. journals that are abstracted, cited, but not used. ${ }^{17}$

As stated above, what use data the authors had was anecdotal (i.e., consisted primarily of the observations of librarians at the home institutions of the scientists in the user group). Nevertheless, when these data are viewed in light of Pan's finding that the number of papers published in a particular journal is a strong indicator of use, together with Hughes's argument that the place of publication also is a strong identifier of journal importance and usefulness, they indicate that the most cited journals listed in table 4 correspond to the first of Dhawan's categories. ${ }^{17,18}$ This list is analogous to the 
TABLE 2

Journals in Which Researchers' Articles Appeared

\section{Journal Name (Date of Inception)}

Rank Number of Articles

Biochemistry (1962)

17

Cell (1974)

Journal of the American Chemical Society (1879)

Journal of Biomolecular NMR (1991)

Nature (1869)

Proceedings of the National Academy of Sciences of the USA (1914)

Journal of Biological Chemistry (1905)

Structure (1993-1998)

Science (1880)

EMBO Journal (1982)

Nature Structural Biology (1994)

Journal of Molecular Biology (1959)

Biophysical Journal (1960)

Molecular and Cellular Biology (1981)

Journal of Physical Chemistry (1896)

Proteins: Structure, Function and Genetics (1987)

$\begin{array}{rr}1 & 17 \\ 2 & 13 \\ 3 & 9 \\ 4 & 8 \\ 4 & 8\end{array}$

Annual Review of Biophysics and

Biomolecular Structure (1972)

Current Opinion in Structural Biology (1991)

Methods in Molecular Biology (1984)

Molecular Pharmacology (1965)

Phytochemistry (1961)

Solid State Nuclear Magnetic Resonance (1992)

Journal of Magnetic Resonance (1969)

Trends in Biochemical Sciences (1976)

$\begin{array}{ll}4 & 8 \\ 5 & 7 \\ 6 & 6 \\ 6 & 6 \\ 6 & 6 \\ 7 & 5 \\ 7 & 5 \\ 8 & 4 \\ 9 & 3 \\ 9 & 3 \\ 9 & 3\end{array}$

Acta Physiologica Scandinavica (1940)

Chemistry and Biology (1994)

Chemistry and Physics of Lipids (1967)

Glycobiology (1990)

FEBS Letters (1968)

Journal of Biological Inorganic Chemistry (1996)

Macromolecules (1968)

Magnetic Resonance in Chemistry (1985)

Molecular Cell (1997)

Oncogene (1987)

Plant Physiology (1926)

Progress in Biophysics and Molecular Biology (1963)

Protein Engineering (1986)

Protein Science (1992)

Bioorganic and Medicinal Chemistry Letters (1991)

Bioorganic Chemistry (1971)

Biochemical Society Transactions (1973)

Letters in Peptide Science (1994)

Folding \& Design (1996-1998)

102

102

$11-1$

$11-1$

$11-1$

$11-1$

$11-1$

$11-1$

$11-1$

$11-1$

$11-1$

$11-1$

$11-1$

$11-1$

$11-1$

$11-1$

$11-1$

11 1

$11-1$

$11-1$

11 
TABLE 3

Ranking by Type of Literature

\begin{tabular}{lcr} 
Type of Materials & Number of Cites & Percent of Citat \\
\hline Journals & 4,073 & $95.10 \%$ \\
Monographs & 175 & $4.09 \%$ \\
In press & 15 & $0.35 \%$ \\
Theses & 10 & $0.23 \%$ \\
Unpublished reports & 10 & $0.23 \%$ \\
Total & 4,283 & $100.00 \%$
\end{tabular}

core journal collection and includes titles such as Science, Nature, Biochemistry, Proceedings of the National Academy of Sciences, Journal of Molecular Biology, Journal of Biological Chemistry, and EMBO Journal, which are likely to be owned by any respectable academic library. These journals are well established, have a high reputation, are multidisciplinary, and reach a large audience of researchers. An argument could be made against the reliability of using place of publication as an indicator of use; for example, individuals just getting started in their research career may publish in second-tier journals, titles they may never read. The user group for this study, however, was composed almost entirely of well-established researchers who were highly unlikely to publish in such journals. Moreover, as already mentioned, the journals where they have published their recent work correspond closely with those they cite, indicating a close match in relative usefulness. Eight of the top ten places of publication as listed in table 2 are among the top ten journals cited. The following journals are ranked in table 4 among the top twenty-five: Nature Structural Biology, Journal of Biomolecular NMR, Proteins, Journal of Magnetic Resonance, Current Opinion in Structural Biology, and Structure with Folding and Design. Nearly all of these titles also appear among the top twentyfive places of publication in table 2 .

Journal of Magnetic Resonance has been included, which is not specifically a structural biology journal, for two reasons. First, it is one of top-tier titles within the user group for both place of publication and citation. Second, as previously mentioned, greater weight has been given to journals covering NMR because that is the focus of the Center. These titles are listed in table 5, together with their impact factors as listed in the 1997 edition of JCR and as calculated for the study's user group. Although these titles are more specialized and thus have a narrower audience than the core journals, they are clearly of great importance to the user group and also fall into Dhawan's first category. For this reason, the authors can make valid collection development decisions with regard to structural biology journals based on the data contained in tables 2 and 4 .

\section{Conclusion}

There are limitations to this study of journal citation data. Other variables affect the citation of articles, such as the importance the individual researchers in the field and the availability of journals to different researchers at different institutions. Moreover, two types of literature that can be very important tend not to be very well cited: the review literature and science news articles. In addition, the authors did not examine other titles of importance to structural biology, such as Journal of Biomolecular Structure and Dynamics or Journal of Structural Biology, because they were not cited by the authors in their sample. This does not mean that these additional journals are not important to the field of structural biology, but only that the user group did not use them during the time period examined. Of these titles, one is new enough (first issue pub- 
TABLE 4

Ranking of Journals According to Frequency Cited

\section{Journal Name (Date of Inception)}

Rank Number of Articles

Biochemistry (1962)

357

Journal of Biological Chemistry (1905)

353

Nature (1869)

290

Cell (1974)

233

Journal of the American Chemical Society (1879)

226

Science (1880)

216

Proceedings of the National Academy

of Sciences of the USA (1914)

Journal of Magnetic Resonance ( 1969)

EMBO Journal (1982)

Journal of Molecular Biology (1959)

Nature Structural Biology (1994)

Journal of Biomolecular NMR (1991)

FEBS Letters (1968)

European Journal of Biochemistry (1967)

Journal of Chemical Physics (1931)

Genes \& Development (1987)

Proteins: Structure, Function and Genetics (1987)

Molecular and Cellular Biology (1981)

Trends in Biochemical Sciences (1976)

Analytical Biochemistry (1960)

Biophysical Journal (1960)

Protein Science (1992)

Methods in Enzymology (1955)

Current Opinion in Structural Biology (1991)

Structure (1993-1998)

Nucleic Acids Research (1974)

Oncogene (1987)

Current Biology (1991)

Biochimica et Biophysica Acta (1947)

Annual Review of Biochemistry (1932)

Journal of Applied Crystallography (1968)

Biopolymers (1961)

Biochemical and Biophysical

$\begin{array}{lll}\text { Research Communications (1959) } & 30 & 19\end{array}$

Journal of Physical Chemistry (1896)

Journal of Molecular Graphics and Modelling (1983)

Biochemical Journal (1906)

Accounts of Chemical Research (1968)

Chemical Physics Letters (1967)

Journal of Virology (1967)

Macromolecules (1968) 


\section{TABLE 4 (CONT.)}

Ranking of Journals According to Frequency Cited

\begin{tabular}{lcc}
\hline Journal Name (Date of Inception) & Rank & Number of Articles \\
\hline Journal of Bacteriology (1916) & 35 & 11 \\
Annual Review of Biophysics and & & \\
$\quad$ Biomolecular Structure (1972) & 35 & 11 \\
Molecular Physics (1958) & 36 & 10 \\
Current Opinion in Cell Biology (1989) & 36 & 10 \\
Biological Magnetic Resonance (1978) & 36 & 10 \\
Protein Engineering (1986) & 37 & 9 \\
BioEssays (1984) & 37 & 9 \\
Journal of Chromatography A (1958) & 38 & 8 \\
Gene (1977) & 38 & 8 \\
Journal of Organic Chemistry (1936) & 39 & 7 \\
Journal of Immunology (1916) & 40 & 6 \\
Journal of Computational Chemistry (1980) & 40 & 6 \\
Molecular and Biochemical Parasitology (1980) & 40 & 6 \\
Molecular Pharmacology (1965) & 40 & 6 \\
Physical Review A (1893) & 40 & 6
\end{tabular}

lished in 1996) to significantly reduce the likelihood of its use in the time period under examination. Although the other has been in existence for more than forty years, its primary focus is on cellular rather than molecular structure.

\section{Thus, although the size of a collection may not be significant, its content is.}

The complex character of structural biology can lead to an overemphasis on the importance of the established, multidisciplinary journals as opposed to the more narrowly focused titles. For example, the large proportion of papers published in and cited from major titles such as Biochemistry, Cell, Nature, and the like may lead some subject bibliographers to de-emphasize titles such as Structure or Nature Structural Biology. However, when such titles are examined in light of their narrow focus, small size, and relative newness, they must be considered to be top-tier journals, particularly within the subdiscipline of structural biology. On this basis, the authors can reliably conclude from their analysis of citation and publication patterns that the following titles were relevant to their user population:

- Nature Structural Biology (1994)

- Journal of Biomolecular NMR (1991)

- Proteins: Structure, Function and Genetics (1987)

- Current Opinion in Structural Biology (1991)

- Structure (1993)

- Journal of Magnetic Resonance (1969)

This conclusion enabled the authors to submit a proposal to their provost for funding for subscriptions to these titles. The conclusion also suggests a strong case for establishing a subscription to Elsevier's ScienceDirect online journal package because many of the important journals are Elsevier titles. Moreover, almost all of the home institutions of the scientists involved in the Center subscribe to ScienceDirect; thus, they will be coming to the City College campus with their expectations formed by their experience with that product.

Some recent research has indicated a lack of statistical correlation between the size of library journal collections and the publishing activity of researchers served 
TABLE 5

Journals Proposed for Subscription and Their Impact Factors

\begin{tabular}{lcccc}
\hline \hline Journal & $\begin{array}{c}\text { Total } \\
\text { Cites }\end{array}$ & $\begin{array}{c}\text { Total } \\
\text { Articles }\end{array}$ & $\begin{array}{c}\text { Impact } \\
\text { Factor } \\
\text { (JCR) }\end{array}$ & $\begin{array}{c}\text { Impact } \\
\text { Factor } \\
\text { (Calculated) }\end{array}$ \\
\hline Journal of Magnetic Resonance & 166 & 2 & $1.784^{*}$ & 83 \\
Nature Structural Biology & 79 & 4 & 10.782 & 19.75 \\
Journal of Biomolecular NMR & 72 & 5 & 5.154 & 14.4 \\
Proteins: Structure, Function and Genetics & 43 & 2 & 4.161 & 21.5 \\
Current Opinion in Structural Biology & 33 & 1 & 7.509 & 33 \\
Structure & 33 & 4 & 7.633 & 8.25 \\
*This number is the average of two impact factors, because in 1997, the Journal of Magnetic \\
Resonance was split into A and B sections. The two sections have since been merged to form a \\
single ournal.
\end{tabular}

by those collections. ${ }^{20}$ Such a finding could be interpreted as supportive of arguments in favor of access (through print and online indexing and abstracting services and the like) as opposed to ownership. Indeed, in an environment of steep inflation rates and scarce resources, such a model would be preferred. Nevertheless, research faculty members continue to express dissatisfaction with the status of libraries because they believe their research needs should be satisfied by the library collections. Moreover, there is a body of research that the authors have already cited that supports the impor- tance of the content of library collections. Thus, although the size of a collection may not be significant, its content is. In the face of smaller journal collections, researchers may maintain high levels of participation in the process of scholarly communications; however, such collections must be focused on the needs of the researchers as indicated by their citation and publication patterns. Ownership of a core of important journals remains the primary means of supporting research, whether that ownership is accomplished through paper subscriptions or various forms of online access.

\section{Notes}

1. These institutions include Albert Einstein College of Medicine of Yeshiva University, City University of New York, Columbia University, Cornell University, Memorial Sloan-Kettering Institute, Mount Sinai Medical School, New York University School of Medicine, Rockefeller University, and the Wadsworth Center of the New York State Department of Health.

2. John C. Kendrew, "Some Remarks on the History of Molecular Biology," Biochemical Society Symposium 30 (1970): 5-10.

3. Christopher M. Smith, "Bioinformatics, Genomics, and Proteomics: Scientific Discovery Advances as Technology Paves the Path," Scientist 14 (Nov. 27, 2000): 26.

4. David C. Phillips, "The Three-dimensional Structure of an Enzyme Molecule," Scientific American 215 (Nov. 1966): 78-90.

5. Stephen S. Hall, "Protein Images Update Natural History," Science 267 (Feb. 3, 1995): 621.

6. Howard D. White and Katherine W. McCain, "Bibliometrics," Annual Review of Information Science and Technology 24 (1989): 119-65.

7. Janet Hughes, "Use of Faculty Publication Lists and ISI Citation Data to Identify a Core List of Journals with Local Importance," Library Acquisitions: Practice and Theory 19 (winter 1995): 403-13.

8. Julie M. Hurd, Deborah D. Blecic, and Rama Vishwanatham, "Information Use by Molecular Biologists: Implications for Library Collections and Services," College E Research Libraries 60 (Jan. 1999): 31-43. 
9. Amy Dykeman, "Faculty Citations: An Approach to Assessing the Impact of Diminishing Resources on Scientific Research," Library Acquisitions: Practice and Theory 18 (summer 1994): $137-46$.

10. Eugene Garfield, “The Impact Factor.” (June 20, 1994). Accessed Jan 24, 2001, http://www.isinet.com/isi/hot/essays/journalcitationreports/7.html.

11. M. B. M. Campbell, "A Survey of the Use of Science Periodicals in Wolverhampton Polytechnic Library," Research in Librarianship 5 (May 1974): 39-71.

12. Elizabeth Pan, "Journal Citation as a Predictor of Journal Usage in Libraries," Collection Management 2 (spring 1978): 29-34

13. Dykeman, "Faculty Citations."

14. Hurd, Blecic, and Vishwanatham, "Information Use by Molecular Biologists."

15. Hughes, "Use of Faculty Publication Lists and ISI Citation Data."

16. S. M. Dhawan, S. K. Phull, and S. P. Jain, "Selection of Scientific Journals: A Model," Journal of Documentation 36 (Mar. 1980): 24-32.

17. Ibid., 29.

18. Pan, "Journal Citation as a Predictor of Journal Usage in Libraries," 32.

19. Hughes, "Use of Faculty Publication Lists and ISI Citation Data," 406.

20. Gary D. Byrd, "Medical Faculty Use of the Journal Literature, Publishing Productivity and the Size of Health Sciences Library Journal Collections," Bulletin of the Medical Library Association 87 (July 1999): 312-21. 